\title{
Mechanical and water absorption properties and morphology of melt processed Zein/PVAl blends
}

\author{
Sandro Junior Vessoni Torres', Gabriela Brunosi Medeiros², Francisco Rosário', Fabio Yamashita ${ }^{3}$, \\ Luiz Henrique Capparelli Mattoso ${ }^{4}$ and Elisângela Corradini ${ }^{1,2 *}$ (i)
}

\author{
'Departamento de Engenharia de Materiais, Universidade Tecnológica Federal do Paraná - UTFPR, \\ Londrina, PR, Brasil
}

${ }^{2}$ Programa de Pós-graduação em Ciência e Engenharia de Materiais, Universidade Tecnológica Federal do Paraná - UTFPR, Londrina, PR, Brasil

${ }^{3}$ Departamento de Ciência e Tecnologia de Alimentos, Universidade Estadual de Londrina - UEL, Londrina, PR, Brasil

${ }^{4}$ Laboratório Nacional de Nanotecnologia para Agronegócio, Empresa Brasileira de Pesquisa

Agropecuária - EMBRAPA, São Carlos, SP, Brasil

*ecorradini@utfpr.edu.br

\begin{abstract}
Blends of zein and poly(vinyl alcohol) (PVAl) were processed in an internal mixer $\left(150^{\circ} \mathrm{C}, 50 \mathrm{rpm}\right)$ for $5-8$ minutes Glycerol and oleic acid were used as plasticizers. The mixtures obtained were then compression molded and further characterized by Fourier transform infrared spectroscopy (FTIR), water-absorption experiments, mechanical tests, and scanning electron microscopy (SEM). FTIR analysis indicated the existence of hydrogen bonding interactions between zein and PVAl. Tensile tests showed that the addition of PVAl increased the flexibility of the blends. The tensile strength ranged from 1.7 to $5.7 \mathrm{MPa}$, elongation at break ranged from 2.7 to $32 \%$ and Young's modulus ranged from 433 to $7371 \mathrm{MPa}$. Water absorption at equilibrium decreased with increasing zein content, which favored a brittle behavior in the zein/PVAl. The blends were immiscible in the composition studied and the presence of voids indicated poor interfacial interaction between the polymers.
\end{abstract}

Keywords: melt processing, oleic acid, glycerol, poly(vinyl alcohol) and zein.

How to cite: Torres, S. J. V., Medeiros, G. B., Rosário, F., Yamashita, F., Mattoso, L. H. C., \& Corradini, E. (2020). Mechanical and water absorption properties and morphology of melt processed Zein/PVAl blends. Polimeros: Ciência e Tecnologia, 30(4), e2020042. https://doi.org/10.1590/0104-1428.10619

\section{Introduction}

Zein is a corn protein that represents about $80 \%$ of the total proteins in corn grains ${ }^{[1]}$. Zein is an amphiphilic protein that has both hydrophobic and hydrophilic characteristics. More than $50 \%$ of its amino acid residues ${ }^{[2]}$ are hydrophobic, including high percentages of leucine (20\%), proline (10\%) and alanine $(10 \%)^{[3]}$.

Several studies have shown the high potential of zein for the production of packaging and edible films because of its film-forming ability, good oxygen and carbon gas barrier and antioxidant properties, and others such as low water solubility, biocompatibility and biodegradability ${ }^{[4-6]}$.

Zein films are produced by two technological processes: a wet process based on solubilization, and a dry process based on the thermoplastic properties of zein under low humidity conditions. Zein films are prepared by dissolution in aliphatic alcohols and further evaporation of the solvent on inert surfaces. Zein films can be obtained by processing in devices such as kneading, blowing and/or extrusion machines $^{[7-9]}$.
Plasticizers such as glycerol, polyols and fatty acids are added during the formation of zein films to improve film flexibility and manageability, since pure zein films are usually very brittle and fragile ${ }^{[10-12]}$. Glycerol is considered a secondary plasticizer for zein and, when used alone, its effect is limited due to its incompatibility with zein ${ }^{[13]}$. Oleic acid, as a hydrophobic molecule, is a primary plasticizer, meaning it can effectively plasticize the zein film on its own with a low level of water vapor barrier ${ }^{[14]}$. Xu et al. ${ }^{[15]}$ studied the effect glycerol and oleic acid mixtures to plasticize zein films. The authors observed by combination of the two plasticizers a synergistic effect in the decreasing in the glass transition temperature $(\mathrm{Tg})$.

Although the addition of plasticizers diminishes the brittleness of zein films, these plasticizers may facilitate the absorption of moisture from highly air humidity, impairing the barrier and mechanical properties of zein films. Blending zein with other polymers is a simple, rapid and low-cost method to overcome those drawbacks. The amphiphilic nature of zein makes it a highly versatile polymer to be 
combined with both hydrophilic and hydrophobic polymers in the production of compatible materials with better properties than the pure constituents. The literature reports on several studies about blends of zein with conventional synthetic polymers, such as polyethylene, nylon ${ }^{[16]}$ and polyvinylpyrrolidone (PVP) ${ }^{[17]}$, and with biodegradable (natural or synthetic) polymers such as starch ${ }^{[18-20]}$, chitosan ${ }^{[21]}$ poly(e-caprolactone) (PCL) $)^{[2]}$, poly(vinyl alcohol) (PVAl) ${ }^{[23]}$, and poly(propylene carbonate) ${ }^{[24]}$, Poly(butylene adipateterephthalate) (PBAT) ${ }^{[9]}$.

The combination of PVAl and zein might be an interesting alternative in the field of biodegradable plastics, since both are biodegradable and processable in the presence of plasticizers, similarly to most conventional synthetic thermoplastic polymers. PVAl is a flexible material and its presence can favors the ductility of zein/PVAl blends. Additionally, the low solubility of zein in water could increase the hydrophobic character of the corresponding zein/PVAl compositions. However, to the best of author's knowledge, only three papers dealing to zein/PVAl blends are reported in the literature ${ }^{[23,25,26]}$. In these studies, the zein/PVAl blends were prepared by casting and using glycerol as plasticizer. So, up to now there is no published report on the melt-processing of zein with PVAl.

Efforts were dedicated in present work for obtaining polymer blends from zein and PVAl, looking optimizing the polymers properties and their processing characteristics. The zein/PVAl blends were obtained by a melting processing. Oleic acid and glycerol were investigated as plasticizers to process the zein/PVAl blends.

\section{Materials and Methods}

\subsection{Materials}

Corn zein (protein) was purchased from Sigma-Aldrich, USA, [9010-66-6, MW: 40 kDa]. Poly(vinyl alcohol) (PVAl) Selvol ${ }^{\mathrm{TM}} 203$ (degree of hydrolysis: 88\%, MW $\sim 18 \mathrm{kDa}$ ) was purchased from Sekisui Chemical, Japan. Analytical grade glycerol and oleic acid were purchased from Synth Reagents, Brazil.

\subsection{Preparation of the blends}

Blends of zein with PVAl (zein/PVAl) were prepared in proportions of $0 / 100,25 / 75,50 / 50,75 / 25$ and $100 / 0(\%, w / w)$, using oleic acid and glycerol as plasticizers. The total content of plasticizers was kept at $20 \%$ by weight with respect to the total polymer mass (dry basis). The glycerol:oleic acid ratio $(\%, \mathrm{w} / \mathrm{w})$ was $1: 0 ; 0.25: 0.75 ; 0.5: 0,5 ; 0.75: 0.25$ and $0: 1$ for $0 / 100,25 / 75,50 / 50,75 / 25$ and $100 / 0$ zein/PVAl blends, respectively.

The polymer powders and plasticizers were premixed in a beaker to ensure good homogenization. They were then processed at $160^{\circ} \mathrm{C}$ for $5-8$ minutes in an internal mixer coupled to a Haake Rheomix 600P torque rheometer operating at a rotor rotational speed of $50 \mathrm{rpm}$. Then, the mixtures were then compression molded at $150^{\circ} \mathrm{C}$ for 5 minutes under a pressure of 5 tons to produce $150 \times 120 \times 2.5 \mathrm{~mm}$ molded sheets.

The processing conditions were defined from the thermal transitions of the polymers and from preliminary tests. Zein is a completely amorphous polymer, with $\mathrm{Tg}$ at about $165^{\circ} \mathrm{C}$, decreasing significantly in response to an increasing degree of plasticization. Lawton ${ }^{[27]}$ showed that the addition of $20 \%$ oleic acid lowers the zeins's $\mathrm{T}_{\mathrm{g}}$ to $80^{\circ} \mathrm{C}$. Zein is thermally stable up to $280^{\circ} \mathrm{C}^{[28]}$. Glycerol well interacts with PVAl. The melting temperature of PVAl (Selvol ${ }^{\mathrm{TM}}$ 203) is in the range of $180-190^{\circ} \mathrm{C}$. When plasticized with glycerol, its melting point reduces, enabling it to be melt processed at temperatures below $180^{\circ} \mathrm{C}$.

\subsection{FT-IR analysis}

FT-IR spectra of samples, after conditioning at $54 \pm 3 \%$ of relative humidity (RH) and $25 \pm 3^{\circ} \mathrm{C}$ for 14 days, were recorded on a Perkin Elmer Spectrum Two FT-IR spectrometer with Universal Attenuated Total Reflectance accessory. The experiments were recorded in the range of 4000 to $400 \mathrm{~cm}^{-1}$, at a resolution of $4 \mathrm{~cm}^{-1}$ and 64 scans.

\subsection{Water absorption}

Circular samples ( $11 \mathrm{~mm}$ in diameter and $2.5 \mathrm{~mm}$ thick), pre-dried overnight at $105^{\circ} \mathrm{C}$, were weighed and placed in hermetically closed containers with $54 \pm 3 \%$ of RH at $25+2^{\circ} \mathrm{C}$, using a saturated $\operatorname{Mg}\left(\mathrm{NO}_{3}\right)$ solution, as prescribed by the ASTM E 104 standard. The amount of water absorbed by the samples was determined by weighing them periodically until reaching constant weight. The water absorption $(W)$ of the samples was

$$
W(\%)=\frac{M_{t}-M_{0}}{M_{0}} \times 100
$$

where $M_{T}$ is the weight at time $t$ and $M_{O}$ is the dry weight before the exposure of samples to $54 \pm 3 \%$ of RH.

\subsection{Tensile tests}

Tensile tests were performed in an EMIC DL3000 universal testing machine equipped with a $50 \mathrm{kgf}$ load cell. The samples, pre-conditioned at $54 \pm 3 \% \mathrm{RH}$ and $25 \pm 3^{\circ} \mathrm{C}$ for 14 days, were prepared according to the ASTM D638M standard, type II. At least 5 samples of each material formulation were tested at a crosshead speed of $2 \mathrm{~mm} / \mathrm{min}$ and room temperature (ca. $25^{\circ} \mathrm{C}$ ).

\subsection{Scanning Electron Microscopy (SEM)}

The specimens were fractured after immersion in liquid nitrogen and sputter-coated with $20 \mathrm{~nm}$ thickness of gold in a Balzers model SCD 50 sputter-coater. SEM images were obtained using a Zeiss Digital Scanning Microscope Model DSM operating at 10 to $15 \mathrm{kV}$ range.

\section{Results and Discussion}

After processing, visual analysis indicated that the processing conditions were sufficient to promote changes in the original structure of the polymers and in their plastification, resulting in thermoplastic materials. It was observed that, as compared to neat zein, the plasticity of polymeric mass improved with the addition of PVAl. 
Figure 1 shows the equilibrium torque curve as a function of the zein/PVAl blend compositions. In the PVAl/glycerol $(0 / 100)$ mixture, the torque reached a stable value of around $0.3 \pm 0.1 \mathrm{Nm}$, and no change was observed in the torque curve after the melting of polymer, indicating that no loss of plasticizer, crosslinking or degradation occurred during the processing of the PVAl / glycerol mixture.

In the case of zein plasticized with oleic acid, the torque increased progressively over time, reaching $16.7 \pm 0.3 \mathrm{Nm}$ after mixing for 5 minutes. The experiment was stopped at this point, when a stiff polymer paste was obtained. The progressive increase in torque suggests the formation of crosslinking between zein chains and/or the formation of interactions between zein and oleic acid. According to Gerrard $^{[29]}$, protein crosslinking can increase the resistance to plastic flow or viscosity, making the polymer more difficult to process. The torque values of the zein/PVAl blends at equilibrium were $1.1 \pm 0.3 \mathrm{Nm}, 2.4 \pm 0.3 \mathrm{Nm}$, and $3.8 \pm 0.3 \mathrm{Nm}$, respectively, for compositions $25 / 75$, $50 / 50$ and $75 / 25$. These values were much lower than that of the plasticized zein, indicating that blend processing was facilitated by the addition of PVAl and glycerol, which reduced the viscosity.

Figure 2 depicts the FTIR spectra of plasticized polymers (PVAl and zein) and their blends. The PVAl spectrum shows a broad band at around $3200-3570 \mathrm{~cm}^{-1}$,

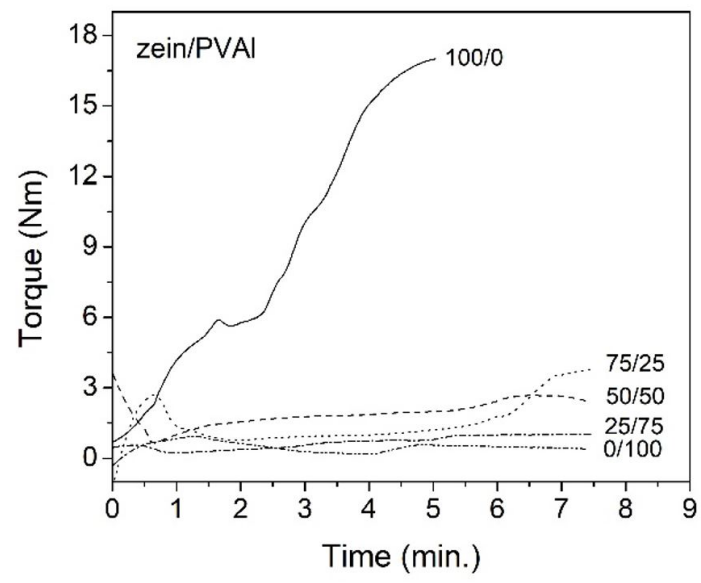

Figure 1. Torque as a function of mixing time of Zein/PVAl blends. which is associated with $\mathrm{O}-\mathrm{H}$ stretching of intermolecular and intramolecular hydrogen bonds. The band at around 2850-3000 $\mathrm{cm}^{-1}$ denotes C-H stretching. The peak at about $1725 \mathrm{~cm}^{-1}$ is due to $\mathrm{C}=\mathrm{O}$ and $\mathrm{C}-\mathrm{O}$ stretching. The peaks at around $1650 \mathrm{~cm}^{-1}, 1370 \mathrm{~cm}^{-1}$ and $1260 \mathrm{~cm}^{-1}$ were attributed, respectively, to absorbed water, $\mathrm{O}-\mathrm{H}$ bending and residual acetate ${ }^{[30]}$. The peak at $1094 \mathrm{~cm}^{-1}$ is related to the $\mathrm{C}=\mathrm{O}$ stretching in the crystalline region of $\mathrm{PVAl}^{[31]}$. The band at $1039 \mathrm{~cm}^{-1}$ is attributed to the $\mathrm{C}-\mathrm{O}$ stretching vibration of primary alcohol in glycerol ${ }^{[32]}$.

The FTIR spectrum of zein shows four characteristic bands ${ }^{[28,33]}$. The band corresponding to stretching of the N-H and $\mathrm{O}-\mathrm{H}$ bonds of the protein amino acids, which appears between 2800 and $3500 \mathrm{~cm}^{-1}$, is called amide A. Another band, which appears at $1650 \mathrm{~cm}^{-1}$, corresponds to carbonyl $(\mathrm{C}=\mathrm{O})$ stretching of amide groups belonging to the peptide groups (amide I). The band at $1540 \mathrm{~cm}^{-1}$ is called amide II and corresponds to the angular deformation vibrations of the $\mathrm{N}-\mathrm{H}$ bond. The band at $1230 \mathrm{~cm}^{-1}$ corresponds to the axial deformation vibrations of $\mathrm{C}-\mathrm{N}$ bond in the blends spectra. One shoulder band observed at around $1710 \mathrm{~cm}^{-1}$ is attributed to the carboxylic $\mathrm{C}=\mathrm{O}$ stretching of the oleic acid ${ }^{[34]}$. This signal was overlapped with band of PVAl in the spectrum of blends. In a study using ${ }^{13} \mathrm{C}$ NMR by Forato et al. ${ }^{[35]}$ showed that interactions between oleic acid molecules and zein occur mainly between carboxylic groups $(-\mathrm{COOH})$ present in oleic acid and with groups $\left(\mathrm{NH}_{2}\right)$ of arginine residues present in the structure of the zein. Gillgren et al. ${ }^{[36]}$ studied the molecular interaction of water and glycerol with zein using FTIR. They reported that water and glycerol bind with the amide groups of zein through hydrogen bonds as they were used as plasticizers. In this work, the effect of water in structure of zein was investigated by the relative heights of the peaks at 1540 and $1515 \mathrm{~cm}^{-1}$ in amide II region for compositions with different moisture contents. It was verified an increase in heights with the water content (results not shown) and similar results were observed by Gillgren et al. ${ }^{[36]}$.

Some slight shifts of the bands of the spectra of zein/ PVAl blends in relation to pure polymer, in the wavenumber range of $1700-1200 \mathrm{~cm}^{-1}$ (Figure $2 \mathrm{~b}$ ) and $3200-3570 \mathrm{~cm}^{-1}$, were observed and suggest possible specific chemical interactions between zein and PVAl and also between these polymers and plasticizers. Interactions between zein and PVAl may occur through the formation of hydrogen
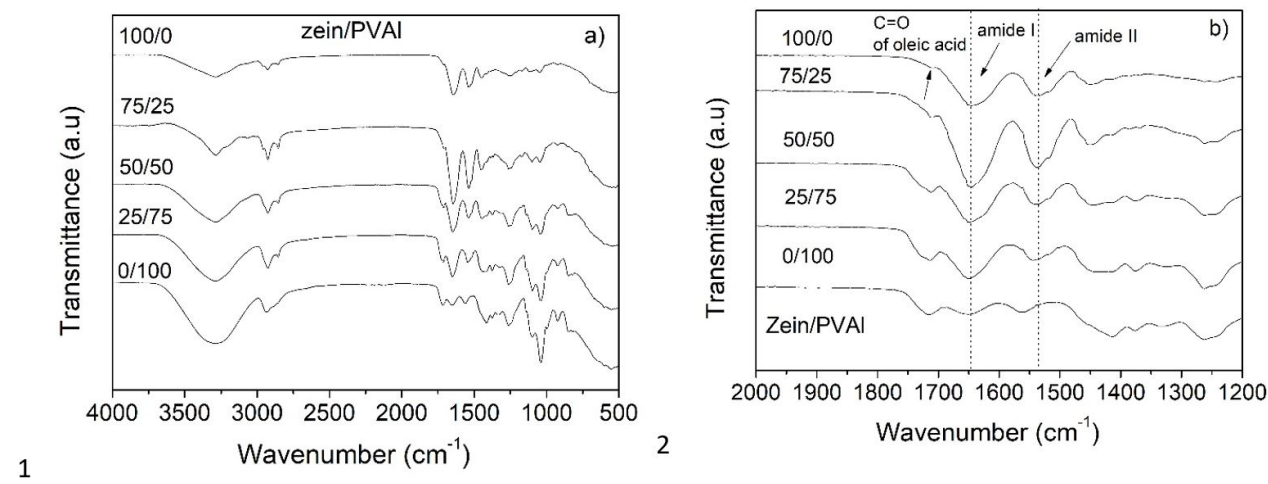

Figure 2. FTIR spectra of Zein, PVAl and their blends. 


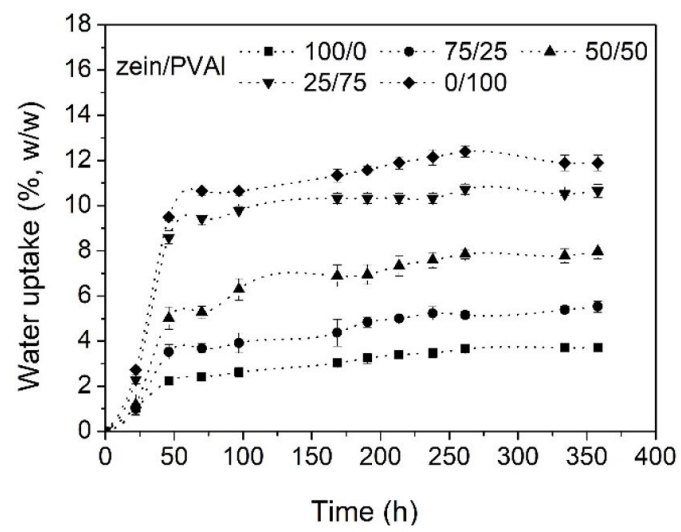

Figure 3. Water absorption at $54 \pm 3 \% \mathrm{RH}$ versus composition of Zein/PVAl blends.

bonds. The $-\mathrm{OH},-\mathrm{NH}_{2}$ and $-\mathrm{C}=\mathrm{O}$ groups in zein are able to form hydrogen bonds with -OH in PVAl. The degree of interaction between the polymers (zein-PVAl) may have been reduced by polymer-plasticizer interactions. The band due to $-\mathrm{OH}$ stretching vibration observed at $3285 \mathrm{~cm}^{-1}$ for zein plasticized; and at $3290 \mathrm{~cm}^{-1}$ for PVAl plasticized was slightly shifted for zein/PVAl blends. The intensity of this band decreased with increasing ration of PVA in the blend. The lowering in intensity may be due to weaker polymer-water interactions at higher concentrations of zein, suggesting a slight dehydration of PVAl after the addition of zein, as reported by Lacroix et al. ${ }^{[25]}$.

Figure 3 illustrates the results of the water uptake experiments. The addition of zein decreased the water uptake at equilibrium of blends with PVAl. This behavior was attributed to the difference in the hydrophilicity of zein and PVAl. Zein is composed of amino acids, many of which have nonpolar side groups, whereas PVAl is highly hydrophilic and interacts more strongly with water than zein.

The water absorbed of the zein-based materials depends also on the nature of plasticizer. Lawton ${ }^{[27]}$ prepared zein films by casting using plasticizers with different degrees of hydrophilicity. He observed that films containing more hydrophilic plasticizers (e.g. glycerol and triethylene glycol) absorbed considerably more water than films containing more hydrophobic plasticizers (dibutyl tartrate and oleic acid). Corradini et al. ${ }^{[37]}$ studied the water absorption properties of starch/zein blends plasticized with glycerol. The results showed that starch/zein plasticized with $22 \%$ of glycerol exhibited higher water uptake value than the obtained for the zein/PVAl plasticized with glycerol and oleic acid. They also verified that the combination of glycerol and oleic acid to plasticize Zein/PVAl blends is better for reducing the water uptake of these blends compared to the use of glycerol alone. Zein/starch blends plasticized with glycerol ${ }^{[37]}$ exhibited the water uptake at equilibrium values in the range from $8.5 \%$ to $10 \%$ when conditioned at $52 \pm 2 \% \mathrm{RH}$. Comparing these values with those obtained for zein/PVAl plasticized with oleic acid and glycerol, it is observed that the water uptake is ca. $20 \%$ lower than zein/starch blends. These differences are partially due to the lower amount of glycerol in the zein/PVAl blends.
Figure 4 illustrates the Young modulus (E), ultimate tensile strength $\left(\sigma_{\text {Max }}\right)$, and elongation at break $\left(\varepsilon_{\text {Max }}\right)$, which were determined from the stress-strain curves at different zein/PVAl blend compositions. Figure 4 illustrates the Young modulus $(\mathrm{E})$, ultimate tensile strength $\left(\sigma_{\mathrm{Max}}\right)$, and elongation at break $\left(\varepsilon_{\text {Max }}\right)$, which were determined from the stress-strain curves at different zein/PVAl blend compositions. The mean values of $\sigma_{\mathrm{r}}$ for the $0 / 100,25 / 75,50 / 50,75 / 25$ and $100 / 0$ zein/PVAl compositions varied in the range of $1.7-5.7 \mathrm{MPa}$. The addition of PVAl caused the $\sigma_{\text {Max }}$ of the blends containing zein to decrease significantly. For example, the zein/PVAl blend with the 50/50 composition showed a $333 \%$ decrease in $\sigma_{\mathrm{Max}}$ in relation to the plasticized zein (composition 100/0). The mean values of Young's modulus (E) for the $0 / 100$, 25/75, 50/50, 75/25 and 100/0 zein/PVAl compositions varied in the range of $433-7371 \mathrm{MPa}$. Zein was more rigid and brittle than PVAl. The value of E of zein was $1370 \%$ higher than that of PVAl, and the addition of zein produced blends that were more rigid than PVAl, with E values increasing to up to $980 \%$ in the $25 / 75$ composition when compared to pure PVAl. The mean values of the elongation at break $\left(\varepsilon_{\text {Max }}\right)$ for the $0 / 100,25 / 75,50 / 50,75 / 25$ and 100/0 zein/ PVAl compositions varied from $2.7-32 \%$. PVAl presenting higher $\varepsilon_{\text {Max }}$ than zein. The behavior of zein/PVAl at 50/50 and $75 / 25$ compositions was similar to that of zein, indicating that the elongation of these blends was strongly reduced by the addition of zein when compared to that of pure PVAl. The 25/75 composition showed $49 \%$ lower elongation than that of pure PVAl. These results suggest that zein had stronger effect on the mechanical properties of the blends than PVAl, since low amount of the former $(25 \%)$ affected this property significantly. The curves of the mechanical properties of the compositions showed a typical behavior of incompatible blends, indicating weak interaction between PVAl and zein. These results were similar to those reported by Corradini et al. ${ }^{[22]}$ for PCL/zein blends, which were also incompatible. Corradini et al. ${ }^{[37]}$ reported that the addition of zein favors the rigidity of zein/starch blends plasticized with glycerol. For zein/starch blends $(0 / 100,25 / 75,50 / 50$, $75 / 25$ and $100 / 0$, wt $\%$ ), containing $22 \mathrm{wt} \%$ of glycerol, the E values ranged from 77 to $1162 \mathrm{MPa}$; the $\sigma_{\mathrm{r}}$ values ranged from 4 to $12 \%$; and $\varepsilon_{\mathrm{r}}$ ranged from 66 to 2 . Leroy et al. ${ }^{[38]}$ verified that, compared to glycerol, the use of (1-butyl-3methyl imidazolium chloride [BMIM]Cl) leads to a more efficient plasticization for starch/zein blends, indicating that a compatibilization between starch and zein blends takes place in presence of [BMIM]Cl. The composition $50 / 50(\mathrm{wt} \%)$ of $\mathrm{starch} /$ zein plasticized with glycerol presented values of $2.5 \mathrm{MPa}\left(\sigma_{\mathrm{r}}\right), 50 \mathrm{MPa}(\mathrm{E})$ and $5 \%\left(\varepsilon_{\mathrm{r}}\right)$, whereas the values for $\sigma_{\mathrm{r}}, \mathrm{E}$ and $\varepsilon_{\mathrm{r}}$ for same composition plasticized with [BMIM]Cl were respectively, $20 \mathrm{MPa}$, 4.0 and $150 \%$. Senna et al. ${ }^{[26]}$ observed that the increase of PVAl ratio increased the toughness of the blends of zein/ PVAl. In another study, Giteru et al. ${ }^{[39]}$ evaluated the effect of the composition of edible films containing zein, chitosan, poly(vinyl alcohol) and poly(ethylene glycol) (PEG400) in mechanical properties of the mixture. They verified that the incorporation of poly(vinyl alcohol) increased the ductility of the composite films. The $\sigma_{\mathrm{r}}$ ranged from 7.0 to $37.5 \mathrm{MPa}, \varepsilon_{\mathrm{r}}$ ranged from 26 to $233 \%$ and $\mathrm{E}$ ranged from 82 to $613 \mathrm{MPa}$. Wei et al. ${ }^{[40]}$ prepared blends of zein and 

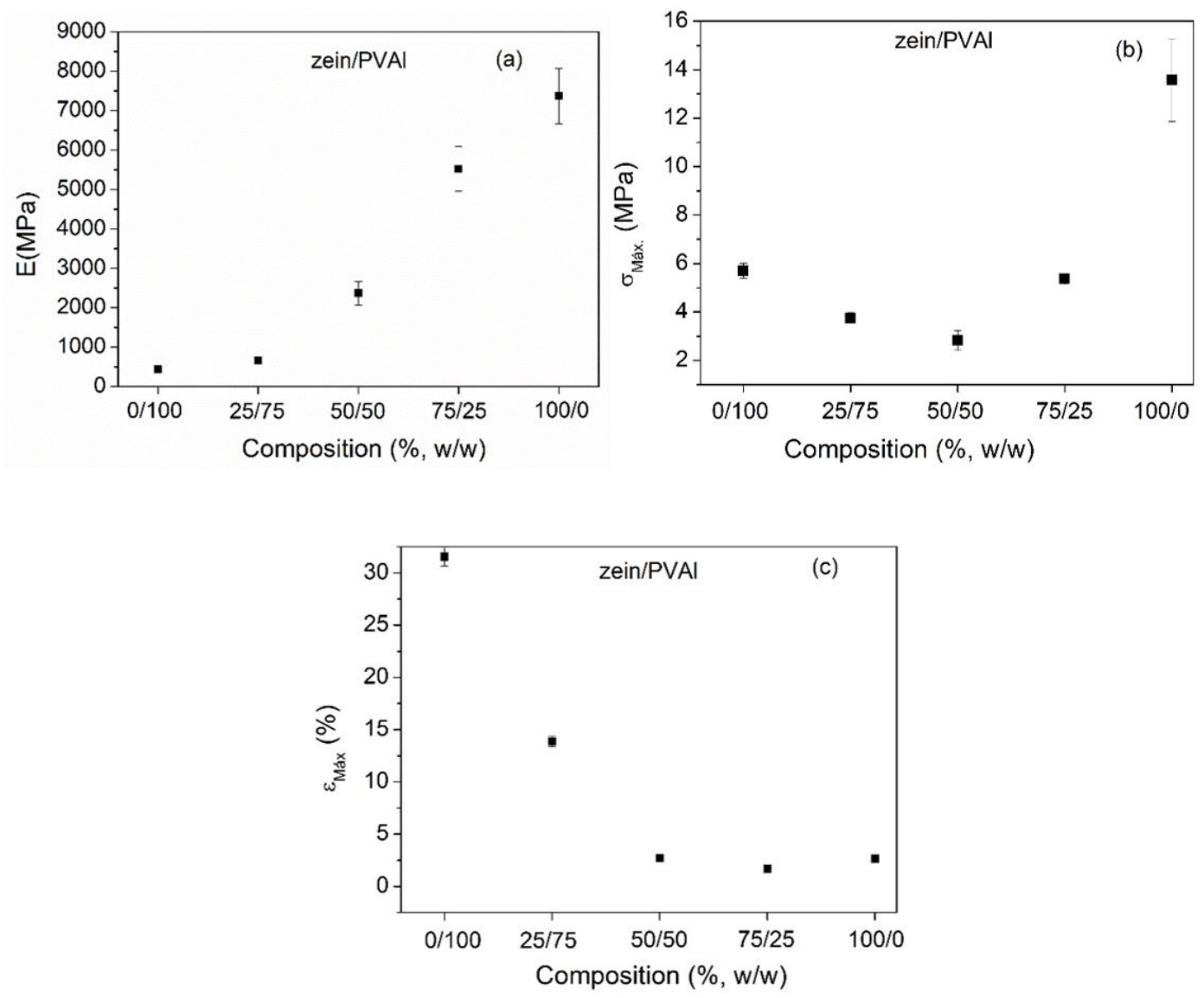

Figure 4. (a) Young's Modulus (E); (b) elongation at break $\left(\varepsilon_{\mathrm{Max}}\right)$; (c) Ultimate tensile strength $\left(\sigma_{\mathrm{Max}}\right)$ as a function of composition of Zein/PVAl blends.

poly(butylene adipate-terephthalate) (PBAT) by reactive blending in the presence of poly(ethylene glycol diglycidyl ether) (PEGDGE). PEGDGE acted as plasticizer and reactive compatibilizer in the PBAT/zein blending system. The values for $\sigma_{\mathrm{r}}, \mathrm{E}$ and $\varepsilon_{\mathrm{r}}$ for the composition $25 / 75(\mathrm{wt} \%$ ) without PEGDGE were, $6 \mathrm{MPa}, 120 \mathrm{MPa}$ and $80 \%$, respectively. When $5 \mathrm{phr}$ (parts per hundreds of mixture PBAT and zein) of PEGDGE was added to $25 / 75$ composition, an increasing of $50 \%$ and $33 \%$ in $\sigma_{\mathrm{r}}$ and $\varepsilon_{\mathrm{r}}$, respectively and a decrease of $38 \%$ in E, were observed.

All the above-mentioned studies showed that the addition of zein favors the rigidity of the blends, increasing their modulus of elasticity and tensile strength and reducing their deformation. Comparing the mechanical properties of cited studies with the results obtained for the blends under study, it was observed that for the most compositions, zein/PVAl exhibited higher $\mathrm{E}$ values, although lower values of $\varepsilon_{\mathrm{Max}}$ and $\sigma_{\text {Max }}$. The $E$ and $\sigma_{\text {Max }}$ values increased with increasing zein content, whereas $\varepsilon_{\text {Max }}$ values decreased. Based on the research reported by Wei et al. ${ }^{[40]}$ and Leroy et al. ${ }^{[38]}$, the utilization of compatilizers can be an alternative for improving mechanical properties of the zein/PVAl blends. It was observed also that oleic acid and glycerol affected the mechanical property of zein/PVAl blends differently. For compositions containing oleic acid content up to $0.5 \%$ (50/50, 75/25 and 100/0 zein/PVAl blends), the $\varepsilon_{\text {Max }}$ values remained approximately constant, whereas $\mathrm{E}$ and $\sigma_{\mathrm{Max}}$ increased. This behavior was probably due to formation of crosslinking between zein chains, as mentioned before. On the other hand, for composition with PVAl content up to $0.5 \%, \varepsilon_{\text {Max }}$ values increased sharply, E decreased and $\sigma_{\text {Max }}$ slightly increased. This is probably explained by strong intermolecular interactions between PVAl and glycerol. A similar effect was observed by Park et al. ${ }^{[41]}$. They added saturated fatty acids (lauric acid, palmitic acid, and stearicpalmitic acid blends) to methyl cellulose/corn zein films and observed a decrease in $\sigma_{\text {Max }}$ but an increase in $\varepsilon_{\text {Max }}$.

Figure 5 shows SEM images of fractured surfaces of PVAl, zein and their blends. The glycerol-plasticized PVAl presented an uniform and continuous surface with some roughness. The zein plasticized showed sheet-like structure, which are probably formed by confinement the orientation correlated protein molecules in the presence of oleic acid ${ }^{[15]}$. Heterogeneous morphologies, such as dispersed morphology and co-continuous morphology, are usually observed in two immiscible blend-melted polymers ${ }^{[42]}$. The morphology of the zein/PVAl blends changed in response to variations in blend composition. The blend containing $25 \%$ PVAl showed PVAl domains in the zein matrix, and the increase the zein content to $50 \%$ led to the formation of a co-continuous morphology, while the blend containing $80 \%$ zein showed 

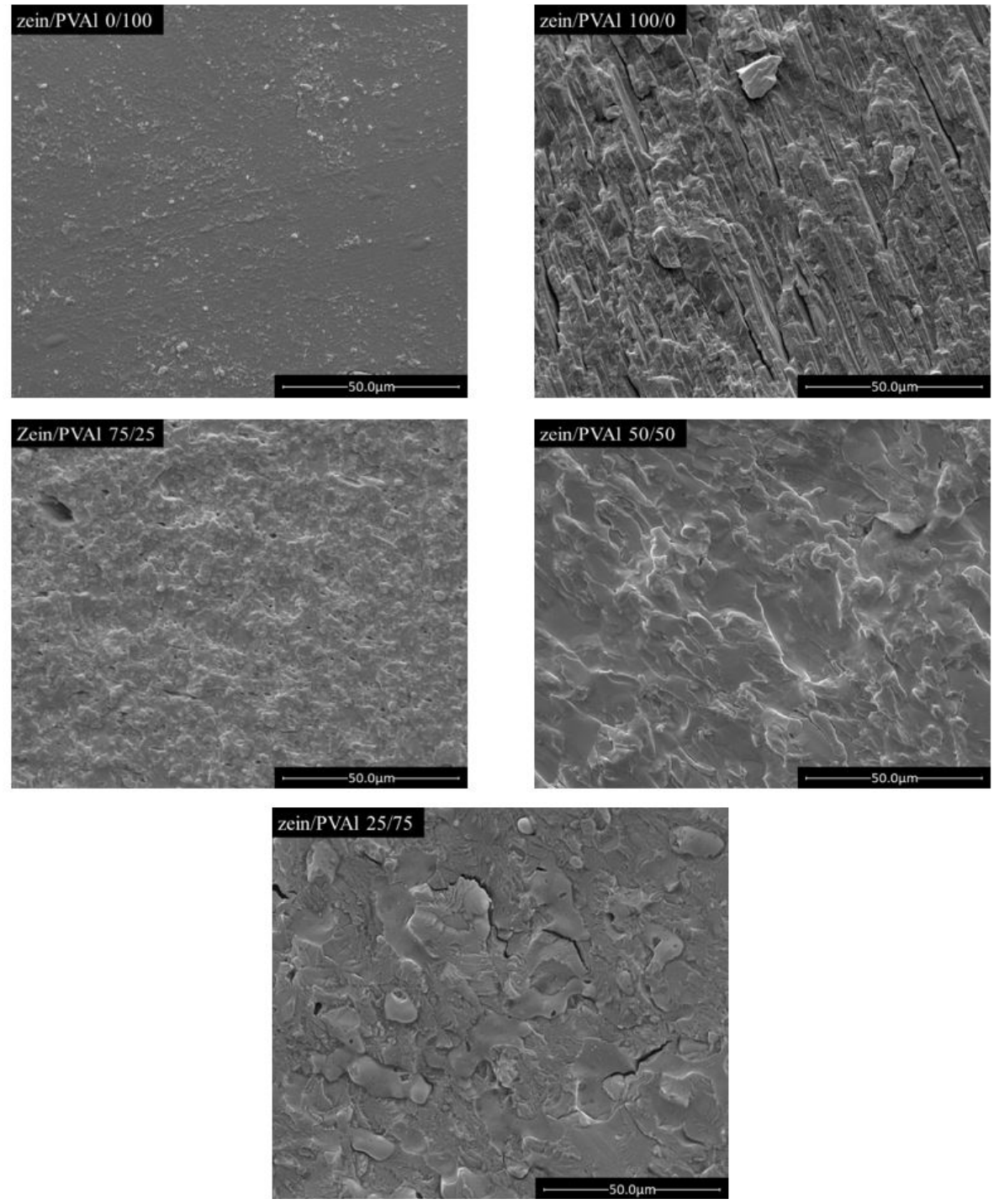

Figure 5. SEM micrographs of the surfaces of the 25/75, 50/50 and 75/25 Zein/PVAl blends.

a PVAl phase dispersed in the zein matrix. The morphology of the blends also revealed interfacial voids, indicating poor adhesion between PVAl and zein phases, which rendered the mechanical properties of the Zein/PVAl blends inferior to those of pure polymers. During processing, zein and PVAl structures undergo physical and chemical changes, depending on the processing conditions. These will dictate these materials' final properties. The incompatibility of Zein/ PVAl blends is related to the extent of polymer-polymer intrachain interactions, which may have been reduced by strong interactions between plasticizers and polymers.

\section{Conclusions}

The results showed the melt-processing feasibility of the zein/PVAl blends plasticized with glycerol and oleic acid. Increasing the concentration of PVAl reduced the viscosity of the blend, thereby improving its processability. The morphology of the blends changed in response to variations in blend composition, and the presence of voids indicated poor interfacial interaction between the polymers. Despite the immiscibility of the blends, their flexibility was improved with addition of PVAl, indicating same degree of compatibility between the polymers. It is possible to combine the good processability and flexibility capabilities of PVAl and the lower water solubility of zein to produce biodegradable films with a promising potential for use as packaging materials. However, further work will be required to fully understand the relationship between processing and chemical structure and properties of zein/PVAl blends plasticized with glycerol and oleic acid.

\section{Acknowledgements}

The authors gratefully acknowledge the Brazil's Conselho Nacional de Desenvolvimento Científico e Tecnológico (CNPq) (Grant No. 408717/2016-5) for the financial support and LNNA-EMBRAPA/CNPDIA for its technical support. 


\section{References}

1. Zhang, H., \& Mittal, G. (2010). Biodegradable protein-based films from plant resources: a review. Environmental Progress \& Sustainable Energy, 29(2), 203-220. http://dx.doi.org/10.1002/ ep. 10463 .

2. Geraghty, D., Peifer, M. A., Rubenstein, I., \& Messing, J. (1981). The primary structure of a plant storage protein: zein. Nucleic Acids Research, 9(19), 5163-5174. http://dx.doi.org/10.1093/ nar/9.19.5163.

3. Cabra, V., Arreguin, R., Galvez, A., Quirasco, M., VazquezDuhalt, R., \& Farres, A. (2005). Characterization of a $19 \mathrm{kDa}$ alpha-zein of high purity. Journal of Agricultural and Food Chemistry, 53(3), 725-729. http://dx.doi.org/10.1021/jf048530s.

4. Corradini, E., Curti, P. S., Meniqueti, A., Martins, A. F., Rubira, A. F., \& Muniz, E. C. (2014). Recent advances in food-packing, pharmaceutical and biomedical applications of zein and zeinbased materials. International Journal of Molecular Sciences, 15(12), 22438-22470. http://dx.doi.org/10.3390/ijms151222438.

5. Luo, Y., \& Wang, Q. (2014). Zein-based micro- and nanoparticles for drug and nutrient delivery: A review. Journal of Applied Polymer Science, 131(16), 40696. http://dx.doi. org/10.1002/app.40696.

6. Chen, Y., Ye, R., \& Liu, J. (2014). Effects of different concentrations of ethanol and isopropanol on physicochemical properties of zein-based films. Industrial Crops and Products, 53, 140-147. http://dx.doi.org/10.1016/j.indcrop.2013.12.034.

7. Shi, W., \& Dumont, M. J. (2014). Review: bio-based films from zein, keratin, pea, and rapeseed protein feedstocks. Journal of Materials Science, 49(5), 1915-1930. http://dx.doi. org/10.1007/s10853-013-7933-1.

8. Almeida, C. B., Corradini, E., Forato, L. A., Fujihara, R., \& Lopes Filho, J. F. (2018). Microstructure and thermal and functional properties of biodegradable films produced using zein. Polímeros: Ciência e Tecnologia, 28(1), 30-37. http:// dx.doi.org/10.1590/0104-1428.11516.

9. Wei, B., Zhao, Y., Wei, Y., Yao, J., Chen, X., \& Shao, Z. (2019). Morphology and properties of a new biodegradable material prepared from zein and poly(butylene adipate-terephthalate) by reactive blending. ACS Omega, 4(3), 5609-5616. http:// dx.doi.org/10.1021/acsomega.9b00210.

10. Ribeiro, W. X., Lopes Filho, J. F., Cortes, M. S., \& Tadini, C. C. (2015). Characterization of biodegradable film based on zein and oleic acid added with nanocarbonate. Ciência Rural, 45(10), 1890-1894. http://dx.doi.org/10.1590/01038478cr20141391.

11. Chen, G., Dong, S., Zhao, S., Li, S., \& Chen, Y. (2019). Improving functional properties of zein film via compositing with chitosan and cold plasma treatment. Industrial Crops and Products, 129, 318-326. http://dx.doi.org/10.1016/j. indcrop.2018.11.072.

12. Liang, J., Xia, Q., Wang, S., Li, J., Huang, Q., \& Ludescher, R. D. (2015). Influence of glycerol on the molecular mobility, oxygen permeability and microstructure of amorphous zein films. Food Hydrocolloids, 44, 94-100. http://dx.doi.org/10.1016/j. foodhyd.2014.09.002.

13. Lawton, J. W. (2002). Zein: a history of processing and use. Cereal Chemistry, 79(1), 1-18. http://dx.doi.org/10.1094/ CCHEM.2002.79.1.1.

14. Lai, H. M., \& Padua, G. W. (1998). Water vapor barrier properties of zein films plasticized with oleic acid. Cereal Chemistry, 75(2), 194-199. http://dx.doi.org/10.1094/CCHEM.1998.75.2.194.

15. Xu, H., Chai, Y., \& Zhang, G. (2012). Synergistic effect of oleic acid and glycerol on zein film plasticization. Journal of Agricultural and Food Chemistry, 60(40), 10075-10081. http://dx.doi.org/10.1021/jf302940j.
16. Selling, G. W., \& Biswas, A. (2012). Blends of zein and nylon-6. Journal of Polymers and the Environment, 20(3), 631-637. http://dx.doi.org/10.1007/s10924-012-0426-5.

17. Sessa, D. J., Woods, K. K., Mohamed, A. A., \& Palmquist, D. E. (2011). Melt-processed blends of zein with polyvinylpyrrolidone. Industrial Crops and Products, 33(1), 57-62. http://dx.doi. org/10.1016/j.indcrop.2010.08.008.

18. Habeych, E., Dekkers, B., Van der Goot, A. J., \& Boom, R. (2008). Starch-zein blends formed by shear flow. Chemical Engineering Science, 63(21), 5229-5238. http://dx.doi. org/10.1016/j.ces.2008.07.008.

19. Corradini, E., Carvalho, A. J. F., Curvelo, A. A. S., Agnelli, J. A. M., \& Mattoso, L. H. C. (2007). Preparation and Characterization of Thermoplastic Starch/Zein Blends. Materials Research, 10(3), 227-231. http://dx.doi.org/10.1590/S1516-14392007000300002.

20. Trujillo-de Santiago, G., Rojas-de Gante, C., García-Lara, S., Verdolotti, L., Di Maio, E., \& Iannace, S. (2014). Strategies to produce thermoplastic starch-zein blends: effect on compatibilization. Journal of Polymers and the Environment, 22(4), 508-524. http://dx.doi.org/10.1007/s10924-014-0685-4.

21. Escamilla-García, M., Calderón-Domínguez, G., ChanonaPérez, J. J., Mendoza-Madrigal, A. G., Di Pierro, P., GarcíaAlmendárez, B. E., Amaro-Reyes, A., \& Regalado-González, C. (2017). Physical, structural, barrier, and antifungal characterization of chitosan-zein edible films with added essential oils. International Journal of Molecular Sciences, 18(11), 2370. http://dx.doi.org/10.3390/ijms18112370.

22. Corradini, E., Mattoso, L. H. C., Guedes, C. G. F., \& Rosa, D. S. (2004). Mechanical, thermal and morphological properties of poly(epsilon-caprolactone)/zein blends. Polymers for Advanced Technologies, 15(6), 340-345. http://dx.doi.org/10.1002/pat.478.

23. Liang, J., \& Chen, R. (2018). Impact of cross-linking mode on the physical properties of zein/PVA composite films. Food Packaging and Shelf Life, 18, 101-106. http://dx.doi. org/10.1016/j.fpsl.2018.10.003.

24. Chen, Y., Ye, R., Li, X., \& Wang, J. (2013). Preparation and characterization of extruded thermoplastic zein-poly(propylene carbonate) film. Industrial Crops and Products, 49, 81-87. http://dx.doi.org/10.1016/j.indcrop.2013.04.040.

25. Lacroix, M., Khan, R., Senna, M., Sharmin, N., Salmieri, S., $\&$ Safrany, A. (2014). Radiation grafting on natural films. Radiation Physics and Chemistry, 94, 88-92. http://dx.doi. org/10.1016/j.radphyschem.2013.04.008.

26. Senna, M. M., Salmieri, S., El-Naggar, A.-W., Safrany, A., \& Lacroix, M. (2010). Improving the compatibility of Zein/ Poly(vinyl alcohol) blends by gamma irradiation and graft copolymerization of acrylic acid. Journal of Agricultural and Food Chemistry, 58(7), 4470-4476. http://dx.doi.org/10.1021/ jf904088y.

27. Lawton, J. W. (2004). Plasticizers for zein: theis effect on tensile properties and water absorption of zein films. Cereal Chemistry, 81(1), 1-5. http://dx.doi.org/10.1094/CCHEM.2004.81.1.1.

28. Magoshi, J., Nakamura, S., \& Murakami, K. I. (1992). Structure and physical-properties of seed proteins. 1. Glass-transition and crystallization of zein protein from corn. Journal of Applied Polymer Science, 45(11), 2043-2048. http://dx.doi.org/10.1002/ app.1992.070451119.

29. Gerrard, J. A. (2002). Protein-protein crosslinking in food: methods, consequences, applications. Trends in Food Science \& Technology, 13(12), 391-399. http://dx.doi.org/10.1016/ S0924-2244(02)00257-1.

30.

Silverstein, R. M., Webster, F. X., \& Kiemle, D. (2005). Spectrometric identification of organic compounds. New York: John Wiley and Sons.

31. Mansur, H. S., Sadahira, C. M., Souza, A. N., \& Mansur, A. A. P. (2008). FTIR spectroscopy characterization of poly 
(vinyl alcohol) hydrogel with different hydrolysis degree and chemically crosslinked with glutaraldehyde. Materials Science and Engineering C, 28(4), 539-548. http://dx.doi.org/10.1016/j. msec.2007.10.088.

32. Zhang, Q., Hu, X. M., Wu, M. Y., Wang, M. M., Zhao, Y. Y., \& Li, T. T. (2019). Synthesis and performance characterization of poly(vinyl alcohol)-xanthan gum composite hydrogel. Reactive \& Functional Polymers, 136, 34-43. http://dx.doi. org/10.1016/j.reactfunctpolym.2019.01.002.

33. Forato, L. A., Bernardes-Filho, R., \& Colnago, L. A. (1998). Protein structure in $\mathrm{KBr}$ pellets by infrared spectroscopy. Analytical Biochemistry, 259(1), 136-141. http://dx.doi. org/10.1006/abio.1998.2599.

34. Rouf, T. B., Schmidt, G., \& Kokini, J. L. (2018). Zein-Laponite (R) nanocomposites with improved mechanical, thermal and barrier properties. Journal of Materials Science, 53(18), 13317-13317. http://dx.doi.org/10.1007/s10853-018-2600-1.

35. Forato, L. A., Doriguetto, A. C., Fischer, H., Mascarenhas, Y. P., Craievich, A. F., \& Colnago, L. A. (2004). Conformation of the Z19 prolamin by FTIR, NMR, and SAXS. Journal of Agricultural and Food Chemistry, 52(8), 2382-2385. http:// dx.doi.org/10.1021/jf035020+.

36. Gillgren, T., Barker, S. A., Belton, P. S., Georget, D. M. R., \& Stading, M. (2009). Plasticization of zein: a thermomechanical, FTIR, and dielectric study. Biomacromolecules, 10(5), 11351139. http://dx.doi.org/10.1021/bm801374q.

37. Corradini, E., Souto de Medeiros, E., Carvalho, A. J. F., Curvelo, A. A. S., \& Mattoso, L. H. C. (2006). Mechanical and morphological characterization of starch/zein blends plasticized with glycerol. Journal of Applied Polymer Science, 101(6), 4133-4139. http://dx.doi.org/10.1002/app.23570.

38. Leroy, E., Jacquet, P., Coativy, G., Reguerre, A. L., \& Lourdin, D. (2012). Compatibilization of starch-zein melt processed blends by an ionic liquid used as plasticizer. Carbohydrate Polymers, 89(3), 955-963. http://dx.doi.org/10.1016/j.carbpol.2012.04.044.

39. Giteru, S. G., Ali, M. A., \& Oey, I. (2019). Solvent strength and biopolymer blending effects on physicochemical properties of zein-chitosan-polyvinyl alcohol composite films. Food Hydrocolloids, 87, 270-286. http://dx.doi.org/10.1016/j. foodhyd.2018.08.006.

40. Wei, B., Zhao, Y., Wei, Y., Yao, J., Chen, X., \& Shao, Z. (2019). Morphology and properties of a new biodegradable material prepared from zein and poly(butylene adipate-terephthalate) by reactive blending. ACS Omega, 4(3), 5609-5616. http:// dx.doi.org/10.1021/acsomega.9b00210.

41. Park, J. W., Testin, R. F., Park, H. J., Vergano, P. J., \& Weller, C. L. (1994). Fatty acid concentration effect on tensile strength, elongation, and water vapor permeability of laminated edible films. Journal of Food Science, 59(4), 916-919. http://dx.doi. $\operatorname{org} / 10.1111 / j .1365-2621.1994 . t b 08157 . x$.

42. Potschke, P., \& Paul, D. R. (2003). Formation of Co-continuous structures in melt-mixed immiscible polymer blends. Journal of Macromolecular Science, Part C: Polymer Reviews, C43(1), 87-141. http://dx.doi.org/10.1081/MC-120018022.

Received: Dec. 23, 2019

Revised: Jan. 26, 2021

Accepted: Jan. 28, 2021 